\title{
MUNICIPAL COASTAL GOVERNANCE PROCESS RESEARCH AND DEVELOPMENT: COASTAL SOCIO-ECOLOGICAL SYSTEM AND ITS GOVERNANCE UNDERSTANDING
}

\author{
Raimonds Ernsteins ${ }^{1}$, Prof.Dr.habil.paed., Erika Lagzdina ${ }^{2}$, MSc.env. and Anita Lontone- \\ Ievina ${ }^{3}$, MSc.env. \\ ${ }_{1,2,3}$ Environmental Science Dept., University of Latvia, Riga, Latvia
}

\begin{abstract}
Understanding and management of the coastal resources in integrated manner, taking into account all sustainability dimensions, since approaching coastal governance as social-ecological system (SES) governance, is still a theoretical and practical challenge for those working in the field, e.g. researchers, politicians, especially for local governments and coastal communities. Integrated coastal management (ICM) is also about creation of such governance systems that allow to integrate stakeholders and diverse knowledge tools and mechanisms to enhance them. The EU BONUS BaltCoast project (2015-2018) provided an internationally acknowledged methodology - System Approach Framework (SAF), that has been adjusted in Latvia's case study for particular situation as not just one topical coastal management problem case, but as the whole rural territories coastal governance process case, being based on research-and-development (R\&D) framework study at Salacgriva local rural municipality. This allowed for SES based assessment of the local coastal governance process with five key coastal governance problem clusters identification. Further on concrete proposals for collaborative and participatory coastal governance innovation development for Latvia's situation were suggested, being based on previously elaborated coastal science-policy interface model application at the local level and, particularly, creation of idea and designing of municipal monitoring system for first time in Latvia. Case study research application and coastal governance development recommendations from pilot practice are presented.
\end{abstract}

Key words: coastal assessment, coastal inhabitants, stakeholders, governance system, collaborative governance,

JEL code: Q20, Q57, Q58

\section{Introduction}

Understanding and management of coastal zone processes and resources is of great economic and social importance as at least half of the world's population resides and works within the coastal zone. Integrated coastal management (ICM) embodies governance system capable to manage multiple uses in an integrated way through the cooperation and coordination of involved stakeholders at different levels of authority and of different economic sectors (Ehler, 2003; Ernsteins, 2010; Ernsteins et al., 2011).

System Analysis Framework (SAF) has been elaborated and now is internationally recognized method equipped with a number of tools for better ICM particularly building on public involvement idea (Ostrom, 2009; Hopkins). SAF method has set a basis for reseach and development (R\&D) type of project that has been implemented in a pilot municipality in Latvia with goal to develop locally feasible tools for coastal resources governance within the context of overall municipal sustainable development governance. Before that SAF relevance has been retrospectively tested also in a number of Baltic Sea Region and also three Latvian case studies selected as the best available ICM application records in the region addressing complex coastal problem situation (Jansen et al., 2016). These Latvian cases demonstrated ckear orientation towards use of the whole set of collaborative environmental communication instruments that was ultimately recognized as key pre-requisite for adequate ICM process management. (Ernsteins, Lontone-Ievina et al., 2017).

During the EU BONUS programme co-financed international project BaltCoast- "A Systems Approach Framework for Coastal Research and Management in the Baltic" (2015-2018) researchand-development framework study was conducted in Latvia with goal to develop locally feasible tools

\footnotetext{
${ }^{1}$ Raimonds.ernsteins@lu.Iv

2 Erika.lagzdina@lu.Iv

${ }^{3}$ Anita.lontone-ievina@lu.Iv
} 
for coastal resources governance within the context of overall municipal sustainable development governance. SAF was methodologically adapted for particular need of assessment and planning of the local level governance process study and development - Salacgriva municipal coastal governance study and proposals for innovative governance instruments were elaborated (Kudrenickis, 2016, Ernsteins, et al., 2017).

\section{Methodological approach}

The SAF method set a basis for research and development (R\&D) frame type of project that has been implemented in a pilot municipality in Latvia - the Salacgriva coastal municipality. The research activities in the pilot territory were conducted step-wise, accordingly to the needs identified in the iterative process of SAF application and adaptation to the municipal coastal governance case as a social-ecological system (SES), as it has been framed by the overall approach of the BaltCoast project and specified for the University of Latvia as a project partner. The activities implemented by the University of Latvia as one of project partners, were based on a case study research (CSR) methodology utilizing the set of complementary and integrative methods. Identification and mapping of all stakeholders and institutions involved in the coastal governance as well as document studies are both the key SAF elements and it is used to explore local practices that form corestones of further to be used for build governance models.

Coastal SES assessment within a SAF methodology was the first research step that leads to identification of complex coastal issue to be addressed through ICM perspective using SAF tools. Assessment was an iterative multi-step process with different levels of engagement of stakeholders and experts. Each next step enriched information basis and extended understanding of the researcher team and also project beneficiaries from the local community on the coastal issues. Findings supplemented or even modified earlier results/conclusions leading to thought through g higher level generalizations for next SAF steps (coastal system formulation and analysis, etc.) (Lagzdina et al., 2017).

To assess significance of the coast in real activities of the local people (bottom-up governance experience), citizen contribution to the coastal management through project initiatives also were studied. The source of information was publicly available information from the Rural Development Service (state institution supervising implementation of the EU support programme LEADER for rural communities) and local initiative group „Jurkante” that officially unifies Vidzeme region communities beyond Salacgriva municipality. The criteria for our selection of the relevant projects include the following aspects: activities for protection of coastal resources; equipping coastal small scale infrastructure; activities improving coastal economic development; improvement of services (better access to services) to people to motivate them to live in the coastal territories.

In September 2015 a complex field study was carried out with aim to obtain as much as possible basic information on the coastal situation and its management of the whole Salacgriva municipality, utilizing two main sources: 1) semi-structured deep interviews with local citizens living in close proximity to the coast (coastal strip) thus having immediate personal experience/relation to the coast. Besides, another selections criterion was for them to be active member/opinion leaders of the society (either belonging to some citizen activist groups, or business etc.) and 2) visual observations and photodocumentation of the coastal SES elements: nature, infrastructure, human pressures, business activities etc. This significantly enriched material for successive analysis. A total of 19 direct interviews took place in eight different coastal strip locations, incorporating two towns (Salacrgiva, Ainazi) and six smaller settlements (villages/communities) along the whole municipal coastal strip 
that stretches for $55 \mathrm{~km}$. Though for this step, it was not meant to interview representatives from all stakeholder groups, as primary goal was to find coast-related people, still key local coastal stakeholder groups were covered: NGOs and citizens (7 respondents), educators (3), business (6), public sector (3).

Next consecutive step in the research accordingly SAF, was involvement of stakeholders in discussion on initial findings on situation with the coastal resources and coast as a whole. This took place in stakeholder seminar held in October, 2015 in Salacgriva, the administrative premises of North Vidzeme Biosphere Reserve (NBR). Goal of seminar was to present results from 19 interviews and other studies, and, introduce initial conclusions that stem into expert done document analysis, as well as to encourage local people to identify collaboratively their interests and explore opportunities for coastal resources conservation, protection, use and development. Even widely announced, the seminar was not fully representative as for all groups of the local coastally inhabiting people (a few from each group: businessmen, NGOs, pensioners, educators, NBR staff, and village elders), even those present were actively engaged in discussions lead for necessary summaries to be done. Importantly, that second separate and complementary meeting was organized with municipal administration and that took place some weeks later. It was attended by the municipal council chair, its deputy in development matters, and executive director who is responsible for daily operations of the municipality.

After each step of field studies and stakeholder discussions, research findings were processes by the key researchers and interim harmonized in project expert meetings with relevant and experienced specialists from various environmental management fields.

\section{Research results}

\subsection{Identification and synthesis of coastal problems}

System analysis of material from all the mentioned studies (except interviews) there was the long list of coastal issues in rural territories established: 19 specific problem areas were withdrawn as the most typical for the particular coastal territory (Lagzdina et al., 2017). During stakeholder seminar some different angle of issues was revealed, as the most of people complaints related to restrictions for coastal management set by the national regulatory acts (particularly, in the fields of environment, health, construction, and entrepreneurship in the very coastal zone). People were convinced that this is a reason why coastal zone is undermanaged and why pressures from human activities lead to the coastal degradation.

A comparison made for coastal priorities derived from two sources of assessment within SAF Issue Identification step - those from system analysis and those for inhabitants' interviews - demonstrated certain similarities, however different levels of generalization and profoundness of analysis should be considered to judge them (Tab.1). The issue of under population in the coastal zone (close proximity to the sea) clearly stays as most critical cause for a number of other, particularly access, maintenance, and infrastructure problems. Insufficient municipal environmental (coastal) management capacity, complemented with limited coastal information a coastal communication in general, are clearly pointing out to need for more systemic coastal governance as a central problem. Unsustainable coastal resource management at the local municipal level is preventing local development and causing coastal degradation what is threatening sustainability of the coast, its ecosystem and resources. 
Priority areas for coastal governance

\begin{tabular}{|c|c|}
\hline $\begin{array}{c}\text { Coastal priorities as result of system } \\
\text { analysis }\end{array}$ & Coastal priorities based on citizen views \\
\hline $\begin{aligned} & \rightarrow \text { Management of sparsely populated/ } \\
& \text { low density coastal territories } \\
& \rightarrow \quad \text { Overall municipal environmental } \\
& \text { management capacity } \\
& \rightarrow \quad \text { Endangered sustainability of unified } \\
& \text { coast specific nature and culture } \\
& \text { heritage that are set as national } \\
& \text { priority } \\
& \rightarrow \quad \text { Coastal communication problems } \\
& \text { Sea-based marine litter /littered beach }\end{aligned}$ & $\begin{aligned} \rightarrow & \text { Access to the sea and coast (access points in unpopulated } \\
& \text { places, lack of coastal communication) } \\
\rightarrow & \text { Overall municipal environmental management capacity } \\
\rightarrow & \text { Insufficient information level of people and institutions and } \\
& \text { passivity in communication } \\
\rightarrow & \text { Access to the coast for people with special needs (access } \\
& \text { points in unpopulated places) } \\
\rightarrow & \text { Biological pollution from rivers to sea } \\
\rightarrow & \text { High seasonal pressures /pollution (in unpopulated places) } \\
\rightarrow & \text { Management of low density and sparsely populated coastal } \\
& \text { territories }\end{aligned}$ \\
\hline
\end{tabular}

The most significant issue is lack of appropriate infrastructure to enhance not only economic development and use of coast for various human activities (tourism as one of the most important elements for local coastal economies), but also for environmental purposes - reducing human impacts on fragile coastal ecosystems.

\subsection{Bottom-up initiatives on the coast: implementation of LEADER projects}

Local initiative group "Jurkante” is the only eligible local (regional) organization that can benefit from the EU LEADER financing as it is established by and unifies interests of wide local stakeholder community. Importantly, this membership organization involves stakeholders from two neighbouring coastal municipalities: Salacgriva and Limbazi. Besides, this membership has to be based on legal entities to meet roject requirements. Thus projects are usually submitted by local municipal administration or local registered NGOs. Therefore, conclusions provided further in analysis shall be considered as merely indicative and they do not characterize all, but active part of locao society.

Territorial analysis of LEADER results reveals that from a total of funding received for projects during implementation period 2009-2014, only $15 \%$ were spent directly on the coast, $59 \%$ were spent in villages or cities directly in the wider coastal zone. And only $15 \%$ of funds were invested directly for the coastal needs, some $31 \%$ were less directly related to these needs. Here is considerably equal intensity of projects number between local administration and citizen groups in Salacgriva municipality. Eight projects were submitted by the municipal administration, but none of them addressed directly coastal issues. Unlike three local NGOs implemented 16 projects out of whom eight were targeted directly to the coast. Te most active of all applicants is NGO Tujaskrasts that acts in one of quite densely populated and attractive for visitor coastal village Tuja.

\subsection{Interviews: coastal governance summary clustering}

Assessment of answers of the municipal stakeholder representatives living in close proximity to the coast is summarized in five key coastal governance problem clusters. More detailed assessment of these issues and identification of governance solutions basically requests further development of existing results of locally/nationally comparatively innovative collaboration governance between the municipal authority and general public and its interest groups. Albeit, variety of general forms of 'top-down' and 'bottom-up' governance have already been successfully practiced and improved in the Salacgriva municipal practice, and it is believed that they can be used as good example for many other municipalities in Latvia.

1) External restriction in the coastal zone and internal disarray - problem governance (conflict governance). Interviewed citizens mentioned firstly restrictions for coastal management due to 
requirements set in the national legislation and, what is even more essential concern, they pointed to the lack of flexibility in attitude of the State Environmental Service (Inspectorate). addressing acute coastal problems or situations of basic development needs. These two obstacles are ones which have been partially blamed for underdeveloped and insufficient coastal infrastructure and high level of littering observed in the coastal dunes, as well as for problems of the coastal accessibility. The access to the coast in some places (particularly in Tuja village and southward it) has been determined by obstacles caused by the private construction, which interlocks spatially the coast. Such construction practice has not been both timely, nor sufficiently regulated and controlled by the local administration. And it has not been properly managed nowadays either, as the current issue of spatial governance. It must be noted that these aggregated factors (in terms of long-term municipal problem governance) impedes development not only of the coastal zone, but also broader coastal territory and municipality as a whole.

2) Insufficient municipal governance capacity - daily management of environmental and coastal issues, as well as insufficient communication with the citizens. As to 'top-down' coastal governance, the stakeholders emphasize that in general their communication with the local administration is good, though not regular, however it lacks environmental and coastal context. In addition, few NGO and business representatives believe that administration's interest, in terms of its capacity in particular, about the coast and its development is superficial, inactive and it is not updated or discussed, nor adequately planned. This particularly applies to the remotendly located rural territories.

3) Insufficient self-governance capacity of the public representation praxis. Public stakeholders lack unified understanding about current coastal problems. Of course, problems in different places quite vary, and their perception by the stakeholders varies as well. The local people do not see coastal problems as outstanding or emergent, thus they do not see need for response. Though there are some exemptions in the attitude. Summarizing pro-active manifestations of public participation in the coastal governance of Salacgriva municipality in terms of 'bottom-up' governance and admitting variety and number of public and stakeholder participation forms and instruments in the municipality, several limiting factors must be recognized. Just to mention the Village elders who are elected by the village people to serve their interests. In general, their activities are not directly targeted neither to environmental, nor coastal issues. Even more, there are identified risks that they represent interests of narrow citizen groups. Interest, though limited, and willingness to deal with environmental and coastal issues has been related with so called consultative bodies (Youth Board and others) having advisory role in communication with the municipal administration. Active participation has been demonstrated by the Fishermen and Anglers Board members. Alike, activities of different citizen stakeholder groups are not targeted to the coast, coastal governance, nor development. Again, there is one exception - NGO Tujaskrasts (Tuja Coast).

4) Lack of coastal development vision and practice. In the context of previously described insufficient capacity of 'top-down' and 'bottom-up' governance, as well as due to the underdeveloped coastal infrastructure, currently it is hardly possible to plan and promote purposefully neither coastal attractiveness by employing possible diverse uses of internal and external resources in their complementarity, from one side, nor at least/to start with short term, seasonal, thematic or other kind of visits to the coast, from the other side. Similarly, it is not possible to implement some of potential municipal development scenarios and use rich and diverse coastal resources in their totality for the municipal territory selectively zoned as $55 \mathrm{~km}$ long coastal territory. This means that there is need for promotion of more active cooperation between some of the coastal stakeholders, as well as 
between them and different state institutions, primarily, environmental, health, and forestry services, and other sectors at the national and regional governance levels.

5) Networking approach of the coastal municipal governance. Due to insufficient governance capacity of the local administration, a public participation approach, that is not yet well manifested here, has to be suggested as a conceptual potential solution for governance of sparsely populated and remotely situated territories. For that, amunicipality has to find governance development solutions, which have to be done selectively, thematically attractively and adapting appropriate instruments. This request employing both the administrative capacity development approach and a coast-targeted public participation approach, which have to be mutually supportive and complementary, thus moving towards collaborative coastal governance practice. Such networking approach of the coastal municipal governance with its focal points in the local administration, and social and business activity centres located along all $55 \mathrm{~km}$ of the coast exercising thematical deepness of the coastal issues in their activities, shall be further discussied for developing integrated governance scenario applicable for coastal rural territories.

\section{Discussion and conclusions}

In most of the rural coastal territories in Latvia local coastal governance is comparatively underdeveloped and limited by lack of main necessary capacities and that result in unsustainable use of the coastal resources, thus preventing local development and causing coastal degradation which remains a threat to sustainability of the resources. It is essential to find ways how to organise coastal governance (the governance process and structure) in the coastal rural territories, which are characterised by a small number of residents and low population density, but a long coastline.

1) Limited capacity of the coastal municipality's administration/planning considerably affects the traditional "top-down" governance approach realisation as well as its application and efficiency for particular coastal governance process development. The solution should be found in complementary further development of the „bottom-up” governance models and instruments, and, strengthening the interaction of the "top-down" and "bottom-up" governance approaches, in order to extend some existing collaboration governance models and practice, to be also oriented towards coastal governance.

2) Coastal governance problematic in Latvian case has typical drivers and derived responses. Firstly, coastal problem governance, particularly in relation to crisis and risk governance, is strongly drived by the external factors (restrictions) which integrate with internal disarray. Municipal governance capacity in performing daily management of environmental and coastal issues is insufficient. Shortcomings are found also at the societal developments, which lacks self-governance capacity of the public representation praxis. There is overall lack of coastal development vision and practice at all local governance spheres. Experience in partnerships and networking approach for the coastal municipal governance is underdeveloped.

3) New approach for science-policy interface model within ICM in Latvia, being based on such local innovation and design of municipal coastal monitoring and related indicators systems, organizing data from natural and social sciences as for SES approach, as well as citizen science mandatory developments provide a basis for eventually sound rural local coastal governce prespective. Municipal coastal monitoring system proposal includes parameters from monitoring systems of all types of planning documents at all local planning levels. System is composed of indicators and planning supervision parameters, including qualitative indicators. 
4) Public monitoring shall constitute a significant part of municipal monitoring system, because ensuring fulfilment of such measurements, for which otherwise data are possible to obtain only as a result of specific monitoring/research. Public involvement is necessary in all monitoring stages, beginning with data obtaining and ending with final monitoring report approval. Collaborative governance can be a crucial factor not only of successful functioning of the monitoring system, but for the functioning of the whole coastal SES governance system.

\section{Acknowledgement}

$R \& D$ data were collected, elaborated and the whole study done within the framework of the BaltCoast project "A Systems Approach Framework for Coastal Research and Management in the Baltic" and with financial support of EU BONUS program and related national co-funding. Authors would like to acnowledge all reserachers and administrators being involved in the project, but, particularly,

Jānis Kaulins and Krista Ošniece for conducting of related studies.

\section{Bibliography}

1. Cepuritis, E., Ulme, J., Graudina-Bombiza, S. (2017). Development of Beach Litter Monitoring on the Latvian Coastline: The Citizen Science Perspective. Journal of Social Sciences, Regional Formation and Development Studies. No. 1 (21), pp.7-18.

2. Cuadrado Quesada, G., Klenke, T., Mejía-Ortíz, L.M. (2018). Regulatory Challenges in Realizing Integrated Coastal Management - Lessons from Germany, Costa Rica, Mexico and South Africa. Sustainability, No. 10, p. 3772.

3. Ehler, C.N (2003). Indicators to Measure Governance Performance in Integrated Coastal Management. Ocean \& Coastal Management, Volume 46, pp.335-345.

4. Ernsteins, R. (2010). Sustainable Coastal Development and Management: Collaboration Communication and Governance. Human Resources - the Main Factor of Regional Development. Journal of Social Sciences, No.3, pp.247-252.

5. Ernsteins, R., Kaulins, J. et al. (2011). Integrated Coastal Management for Local Municipalities in Latvia: Sustainability Governance and Indicator System. WIT Transaction. Volume 149, pp.29-40.

6. Ernsteins, R., Kudrenickis, I., Lontone-Ievina, A. et al. (2017). Municipal Sustainable Coastal Governance: Participatory Approaches for System Analysis and for Local Monitoring Development. WSEAS Transactions on Environment and Development, Volume 13, pp.276-290.

7. Ernsteins, R., Lontone-Ievina, A. et al. (2017). Integrated Coastal Management Practice Case Studies: Deficiency of Collaboration and Socio-Ecological System Approaches". Book Series: Economic Science for Rural Development. Agriculture University of Latvia, Jelgava, Latvia. Issue 45, pp.63-70.

8. Jansen, H., Ernsteins, R., Stottrup, J., Dinesen, G., Povilanskas, R., (2016). A retrospective analysis of best practice Integrated Coastal Management cases around the Baltic Sea. International conference, 7th European Coastal Lagoons Symposium. Vindicating the biological and socioeconomical importance of transitional waters, Thesis compendium, Spain, Murcia.

9. Hopkins, S., Bailly, D. et al. (2012). A Systems Approach Framework for the Transition to Sustainable Development: Potential Value Based on Coastal Experiments. Ecology and Society, Volume 17, Issue 3, p.39.

10. Kalpakis, V. et.al. (2019). An integrated coastal zone observatory at municipal level: the case of Kavala Municipality, NE Greece. Journal of Coastal Conservation, Volume 23, pp.149-162.

11.Kaulins, J., Ernseins, R., Kudrenickis, I. (2017). Indicator systems for municipal sustainable development governance: prerequisites for design and implementation. Ecosystems and Sustainable Development XI. WIT Transactions on Ecology and The Environment, Volume 214, pp.35-45.

12. Lagzdina, E., Kudrenickis, I., Ernsteins R., et.al. (2017). Coastal Sustainable Development Studies in Latvia: Integrated Local Social-Ecological Systems Governance. Regional Formation and Development Studies, Volume 1, Issue 21, pp.83-96.

13. Lapinskis, J. (2017). Coastal Sediment Balance in the Eastern Part of the Gulf of Riga (2005-2016). Journal Baltica, Volume 30, Issue 2, pp.87-95.

14. Ostrom, E. (2009). A General Framework for Analysing Sustainability of Social-Ecological Systems. Science, No. 325, pp.419-422.

15. Schernewski, G., Schönwald, S., Kataržyte, M. (2014). Application and evaluation of an indicator set to measure and promote sustainable development in coastal areas. Ocean \& Coastal Management, Volume 101, pp.2-13.

16. Schumacher, J., Schernewski, G. Bielecka, M. et al. (2018). Methodologies to support coastal management - A stakeholder preference and planning tool and its application. Marine Policy, Volume 94, pp.150-157. 
17. Ulme J., Graudina-Bombiza, S., Ernsteins, R. (2017). Beach Marine Litter Monitoring: Citizen Science Data Series for Coastal Monitoring Development and Governance in Latvia. Vienna GREEN Conference Proceedings, Volume 17, Issue 33, pp.91-102.

18. H. Jansen, R. Ernsteins, et al., "A retrospective analysis of best practice Integrated Coastal Management cases around the Baltic Sea," in European Coastal Lagoons Symposium. Abstracts Book. Marcos C., PerezRuzafa A., Perez-Marcos M., (eds.), Compobell, Murcia: pp. 212, 2016. 